\title{
Cyclic tensile stretch modulates osteogenic differentiation of adipose-derived stem cells via the BMP-2 pathway
}

Xingmei Yang', Ping Gong', Yunfeng Lin', Lirong Zhang ${ }^{3}$, Xiaoyu Li', Quan Yuan', Zhen Tan², Yongyue Wang'2, Yi Man², Hua Tang²

1State Key Laboratory of Oral Diseases, Sichuan University, China

2Oral Implant Centre, West China College of Stomatology, Sichuan University, China

3Sichuan Centre for Disease Control and Prevention, Chengdu, China

Submitted: 13 March 2009

Accepted: 5 May 2009

Arch Med Sci 2010; 6, 2: 152-159

DOI: $10.5114 /$ aoms.2010.13886

Copyright @ 2010 Termedia \& Banach

\section{Abstract}

Introduction: Mechanical forces play critical roles in the development and remodelling process of bone. As an alternative cell source for bone engineering, adipose-derived stem cells (ASCs) should be fully investigated for their responses to mechanical stress and the mechanisms responsible for osteogenic induction in response to mechanical signals.

Material and methods: We hypothesized that appropriate application of uniaxial cyclic tensile strain to ASCs could increase bone morphogenetic protein-2 (BMP-2) expression and improve osteogenesis of ASCs. To test our hypothesis, ASCs from the same flask of the same donor were subjected to tensile strain with different patterns in order to eliminate the difference of donor site and passage. After surface markers investigation, the osteo-induced ASCs were subjected to uniaxial cyclic tensile stretch with the following two loading patterns: long duration continuous pattern $(6 \mathrm{~h}, 1 \mathrm{HZ}, 2000 \mu \varepsilon)$ and short duration consecutive pattern (17 min every day for 10 consecutive days, $1 \mathrm{HZ}$, $2000 \mu \varepsilon$ ). Then osteogenic related genes were analysed by real-time PCR.

Results: The ASCs were positive for the markers STRO-1, CD90 and CD44 and negative for CD34. Cyclic tensile strain of 6 continuous h' duration significantly increased gene expressions of BMP-2 and Runx2, and depressed OCN mRNA expression. In contrast, mechanical loading of 17 min every day did not significantly affect gene expression of BMP-2, Runx2, OCN or ALP.

Conclusions: We indicate that ASCs may sense mechanical loading in a durationdependent manner and cyclic tensile stretch may modulate the osteogenic differentiation of ASCs via the BMP-2 signalling pathway.

Key words: adipose-derived stem cells, mechanical stress, osteogenesis, BMP-2.

\section{Introduction}

Abundant experimental evidence has demonstrated the multidifferentiation ability of adipose-derived stem cells (ASCs) isolated from human and other species. The osteogenic differentiation potential of ASCS has been exploited for current treatment of skeletal defects and deficiencies. Mechanical force is one of the fundamental biological factors that stimulate fracture healing and the remodelling process of bone [1, 2]. Furthermore, mechanical stress has been indicated as an anabolic factor for osteogenic differentiation of bone mesenchymal stem cells (BMSCs) or osteoblasts in the application of regenerative medicine [3-7]. Therefore,
Corresponding author:

Prof. Ping Gong, PhD

Oral Implant Centre

West China College

of Stomatology

Sichuan University

No. 14, 3rd Section

Renmin Nan Road

Chengdu, 610041, P. R. China

E-mail:

dentistgong@hotmail.com 
the signalling pathway of mechanical signals has undergone elaborate investigations [5, 8-11]. In parallel, the responses to mechanical stress of ASCs should be fully understood before they are applied in bone tissue engineering.

Previous investigations suggested that pulsating fluid flow was able to up-regulate some corresponding molecules such as cyclooxygenase-2 gene expression, nitric oxide production, polyamines levels, and paladin [12-14]. However, the osteogenic markers responsible for different patterns of mechanical stress need to be further investigated.

Bone morphogenetic proteins (BMPs) are among the stimulators of bone formation and play a central role in controlling the proliferation and differentiation of osteoblasts. BMPs, especially BMP-2 and BMP-4, exert a biological function by binding to a heterodimeric receptor complex at the cell membrane that transduces the signal into the cell [15]. Runt-related transcription factor 2 (Runx2) acts as a platform through which multiple external signals are integrated, and can be activated by BMP-2 [2]. The expression of Runx2 continues to modulate bone formation by regulating the activity of differentiated BMSCs or osteoblasts [16]. Runx2 induces the expression and synthesis of osteocalcin (OCN), alkaline phosphatase (ALP) and collagen type I (Col-1), which are involved in different stages of osteogenic differentiation $[15,17]$.

Therefore, the aim of the present study is to investigate the effects of uniaxial cyclic tensile stretch on the osteogenic differentiation of ASCs. We hypothesized that appropriate application of uniaxial cyclic tensile strain to ASCs could increase BMP-2 expression and improve osteogenesis of ASCs.

\section{Material and methods}

\section{Adipose-derived stem cells isolation and culture}

Adipose-derived stem cells from the same flask of the same donor were subjected to tensile strain with different patterns in order to eliminate the difference of donor site and passage. Adiposederived stem cells were isolated from 3 male Sprague-Dawley rats less than 4 weeks old, as described by Zuk et al. [18]. The rat was prepared with standard sterile technique to excise the inguinal fat pads, following protocols approved by the IACUC at Sichuan University. The obtained tissue was washed twice with phosphate-buffered saline (PBS, pH 7.4) supplemented with streptomycin sulfate $(500 \mathrm{~g} / \mathrm{ml})$ and penicillin $(600 \mathrm{~g} / \mathrm{ml})$ and then incubated in $\alpha$-modified Eagle's medium ( $\alpha$-MEM; Gibco, Paisley, UK) and finely minced into small pieces of $0.5 \mathrm{~cm}^{3}$. The fine tissue was digested by $0.05 \%$ type 1 collagenase (Sigma, St. Louis, MO) with vigorous shaking for
$40 \mathrm{~min}$ at $37^{\circ} \mathrm{C}$. Floating populations were removed by centrifugation at $1200 \mathrm{rpm}$ ( $250 \mathrm{~g}$ ) for $8 \mathrm{~min}$ and cells were pelleted. A single-cell suspension was obtained and re-suspended in culture medium composed of $\alpha$-MEM supplemented with $10 \%$ fetal bovine serum (FBS, Gibco, Paisley, UK) and finally seeded on the plastic flask for the final isolation step selected for the plastic adherent populations. Cells were cultured at $37^{\circ} \mathrm{C}$ in a $90 \%$ humidified atmosphere and $5 \% \mathrm{CO}_{2}$ and were used for the following test.

\section{Investigation of surface markers}

The cells were analysed by immunofluorescent staining for STRO-1, and immunocytochemical staining for CD34, CD44 and CD90. Briefly, cells in passage 3 were seeded on a 6-well culture plate and grown until they reached $80 \%$ confluence. They were washed with PBS 3 times for 5 min each in a shaker and then incubated with $0.2 \%$ Triton $\mathrm{X}-100$ in PBS for $20 \mathrm{~min}$ at room temperature; this was followed by incubation with $10 \%$ goat serum in PBS for $1 \mathrm{~h}$ at room temperature. Primary antibodies of STRO-1 (R\&D systems, Minneapolis, MN, USA) were applied for $1 \mathrm{~h}$ at $37^{\circ} \mathrm{C}$, and then washed with PBS in a shaker. FITC-labelled secondary antibody (goat anti-mouse: Zymed, CA, USA) was applied for $1 \mathrm{~h}$ at $37^{\circ} \mathrm{C}$ away from light, then washed with PBS. The slides were then examined with a Leica Inverted Fluorescence Microscope. CD34, CD44 and CD90 (Lab VisionNeomarkers, Fremont, CA, USA) were analysed by immunocytochemical staining. Briefly, after incubation with primary antibodies, cells were incubated with biotinylated anti-immunoglobulin and reagent using labelled streptavidin-biotin (LSAB) kit peroxidase (Dako, Carpinteria, CA, USA). The peroxidase reaction was visualized with $0.01 \% \mathrm{H}_{2} \mathrm{O}_{2}$ and 3,3'-diaminobenzidine under light microscopy. The nuclei were re-stained with haematoxylin.

\section{Application of cyclic tensile stretch}

Force-loading plates were made out of the bottom of the BD Falcon ${ }^{\top M} 75 \mathrm{~cm}^{2}$ cell culture flask (BD Bioscience, CA, USA), $7.8 \times 3.8 \mathrm{~cm}$ in size and $1.2 \mathrm{~mm}$ thick. Adipose-derived stem cells in passage 3 were seeded on the loading plates at a density of $2 \times 10^{5}$ cells per plate and the plates were divided into 10 different groups with 3 samples for each group (Table I). Every plate was kept in glass culture dishes of $9 \mathrm{~cm}$ in diameter. When cells were totally attached to the plates $6 \mathrm{~h}$ later, the culture medium was replaced with osteogenic medium containing $\alpha$-MEM supplemented with 10\% FBS, $0.1 \mu \mathrm{M}$ dexamethasone (Sigma), $10 \mathrm{mM}$ glycerol phosphate (Sigma), and $50 \mathrm{mM} \mathrm{L-ascorbic} \mathrm{acid-2-phosphate}$ (Sigma) [19]. After being osteo-induced for $48 \mathrm{~h}$, 
Table I. ASC stretching and sample collection protocol in this study

\begin{tabular}{|lcccc|}
\hline \multirow{2}{*}{$\begin{array}{l}\text { Long duration } \\
\text { continuous pattern }\end{array}$} & \multicolumn{4}{c|}{ Short duration consecutive pattern } \\
\cline { 2 - 5 } & Day 1 & Day 3 & Day 7 & Day 10 \\
\hline $6 \mathrm{~h}$ cyclic stimulation & 17 min cyclic & 17 min cyclic & 17 min cyclic & 17 min cyclic \\
at $1 \mathrm{~Hz}$. & stimulation at $1 \mathrm{~Hz}$. & stimulation at $1 \mathrm{~Hz}$. & stimulation at $1 \mathrm{~Hz}$. & stimulation at $1 \mathrm{~Hz}$. \\
6 PCR samples & 6 PCR samples & 6 PCR samples & 6 PCR samples & 6 PCR samples \\
\hline
\end{tabular}

cells were subjected to uniaxial cyclic tensile stretch by a 4-point bending mechanical loading device [20-22] with the following protocols: long duration continuous pattern and short duration consecutive pattern (Table I). Osteogenic medium was changed every day and the manipulation was done very carefully to prevent contamination. Each experiment was carried out 3 times and all measurements started $2 \mathrm{~h}$ after the last strain cycle.

\section{Analysis of mRNA by real-time PCR}

Total RNA extraction was started immediately after stretching using Trizol reagent (Invitrogen, Carlsbad, CA, USA) according to the manufacturer's instructions. Total RNA integrity was verified by $1.2 \%$ agarose gel electrophoresis and its yield and purity were verified by the ratio of $A$ (260)/A (280) using UV-spectroscopic analysis. Then cDNA synthesis was performed by reverse transcriptase (Takara Biotechnology, Co., Ltd. Japan). Preparations of cDNA were checked by spectrophotometry and gel electrophoresis. Primers determined through the established GenBank sequence are listed in Table II. Real-time PCR was run in the ABI PRISM 7300 Sequence Detection system (Applied Biosystems, Foster (ity, USA) using the hot-start DNA Master SYBR Green I Kit (Takara Biotechnology, Co., Ltd. Japan) with the following programme: $95^{\circ} \mathrm{C}$ for $10 \mathrm{~min} ; 40$ cycles of $95^{\circ} \mathrm{C}$ for $15 \mathrm{~s}$ and $60^{\circ} \mathrm{C}$ for $1 \mathrm{~min}$, followed by melting curve analysis. The specificities of the PCR products were verified by conducting melting curve analyses between 60 and $95^{\circ} \mathrm{C}$.

With the LightCycler software, the crossing points were assessed and plotted versus the serial dilution of known concentrations of the standards derived from each gene. PCR efficiency (E) was obtained by using the formula $\mathrm{E}=10^{-1}$ /slope. Data were used only if the PCR efficiency calculated was between 1.85 and 2.0. Values of relative gene expression were normalized by the house keeping gene glyceraldehyde 3-phosphate dehydrogenase (GAPDH).

\section{Statistical analysis}

SPSS 13.0 software (SPSS Inc., Chicago, IL) was used for statistical analysis. To quantitatively analyse the gene expression, mean values and standard errors of the mean (SEM) were calculated. A general linear model for repeated measurement analysis was used to study the influence of factors on cell differentiation, and the Bonferroni method was applied for multiple comparisons. Furthermore, the correlation between gene expressions was analysed by Pearson's test. Differences at a probability of less than 0.05 were considered statistically significant.

\section{Results}

\section{Primary culture and phenotypic profile of adipose-derived stem cells}

The cell mass of ASCs grew slowly and single colonies could be identified after 4-5 days of culture, finally reaching $80 \%$ confluence after 7-10 days in primary culture. However, ASCs grew at a rapid rate in the second passage and presented a homogeneous elongated spindle and polygonal fibroblastic shape.

We used the $3^{\text {rd }}$ passage of ASCs to investigate the CD phenotypes and STRO-1 phenotype. As we expected, CD44 (Figure 1B) and CD90 (Figure 1C) were expressed on ASCS. STRO-1, a marker for cells with multi-lineage potential, was also expressed (Figure 1D). In contrast, CD34, which represents the

Table II. Real-time PCR primer description

\begin{tabular}{|c|c|c|c|c|}
\hline Symbol & Sense $\left(5^{\prime}-3^{\prime}\right)$ & Antisense $\left(5^{\prime}-3^{\prime}\right)$ & $\begin{array}{l}\text { Genbank } \\
\text { accession }\end{array}$ & $\begin{array}{l}\text { Product } \\
\text { size [bp] }\end{array}$ \\
\hline GAPDH & TATGACTCTACCCACGGCAAGT & ATACTCAGCACCAGCATCACC & NM_017008 & 138 \\
\hline OCN & GACCСTCTCTCTGCTCACTCTG & САCСTTACTGCCCTCCTGCTT & NM_013414 & 124 \\
\hline ALP & CCTAGACACAAGCACTCCCACTA & GTCAGTCAGGTTGTTCCGATTC & NM_013059 & 138 \\
\hline Runx2 & TTCGTCAGCGTCCTATCAGTTC & CTTCCATCAGCGTCAACACC & XM_0010669 & 150 \\
\hline BMP-2 & GTGAGGATTAGCAGGTCTTTGC & CTCGTTTGTGGAGTGGATGTC & NM_017178 & 109 \\
\hline
\end{tabular}



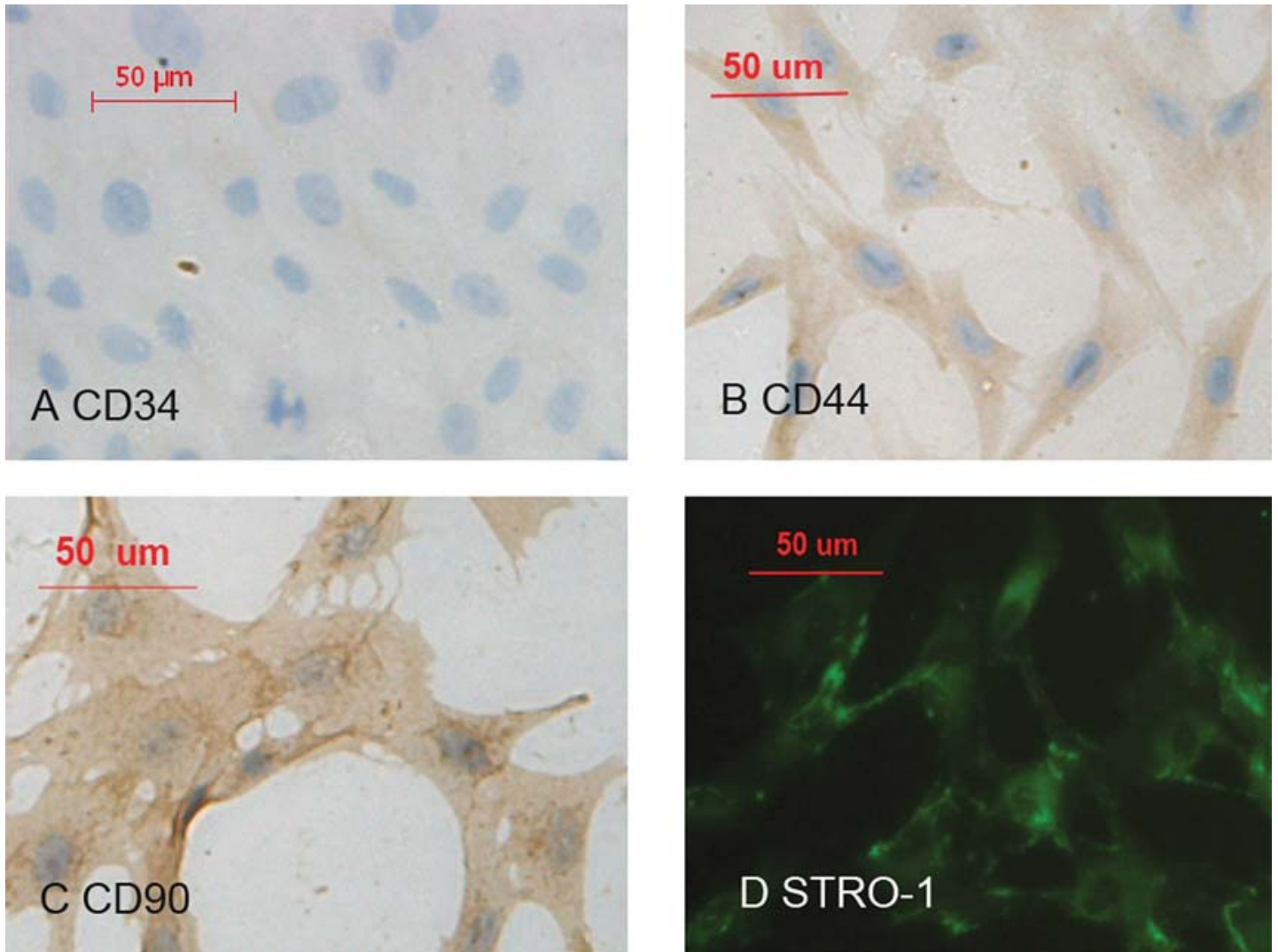

Figure 1. Different expression of surface markers on ASCs detected by immunocytochemical staining analysis for CD34 (A), CD44 (B), and CD90 (C); STRO-1 (D) was detected by immunofluorescent staining (magnification $\times 200$ ). ASCs from the same donor were expanded to passage 3 when they underwent the staining analysis

haematopoietic lineage marker, was negative [23] (Figure 1A). Although some studies have found that CD34 was present on human ASCs early in passage, which is a phenotypic characteristic different from BMSCs [23, 24], species variation may exist, as studies of murine adipose tissue demonstrated that the CD-34 negative SVF populations were also enriched for ASCs [25].

\section{Influence of cyclic tension stretch on cell orientation and alkaline phosphatase and osteocalcin expression}

Different loading patterns had different effects on the orientation of cells. When subjected to the short duration of 17 min every day for 10 days, the cells presented a particular orientation away from the direction of the long axis of the plate from the $4^{\text {th }}$ day of stretching (Figure $2 A$ ). In contrast, cells subjected to $6 \mathrm{~h}$ of stretching and the control group showed no particular orientation (Figure 2B).

To investigate the effect of mechanical strain on the osteogenic differentiation process of ASCs, the ALP and OCN mRNA expression was quantitatively analysed. Alkaline phosphatase overall was slowly increased by stress loading, while the control group maintained a steady level. However, there is no significant difference between loading groups and controls (Figure 3A). Overall, cyclic tensile stretch for 17 consecutive min did not significantly change the mRNA expression of OCN. Analysis of the between-subject effects showed that stretching significantly decreased OCN mRNA expression $(p<0.05)$ (Figure 3B). Seventeen min duration of loading for various days showed a peak expression of ALP and OCN on the $7^{\text {th }}$ day in the loading group (Figure 3).

\section{Cyclic tension strain up-regulated the osteogenic regulation genes}

To investigate the molecular mechanism during the osteogenic process of ASCs treated with cyclic tension strain and osteogenic medium, we determined the mRNA level of BMP, a potential osteogenic differentiation factor, in vitro, and Runx2, the molecular biomarker in the osteogenic process and an important transcription factor that regulates osteogenic differentiation.

The within-subjects effects analysis indicated that loading time had a significant effect on BMP-2 mRNA expression. Duration of 6 h' loading up-regulated the BMP-2 expression significantly compared with the short time loading duration of 17 min for various days; in addition, analysis of between-subject effects showed that mechanical 

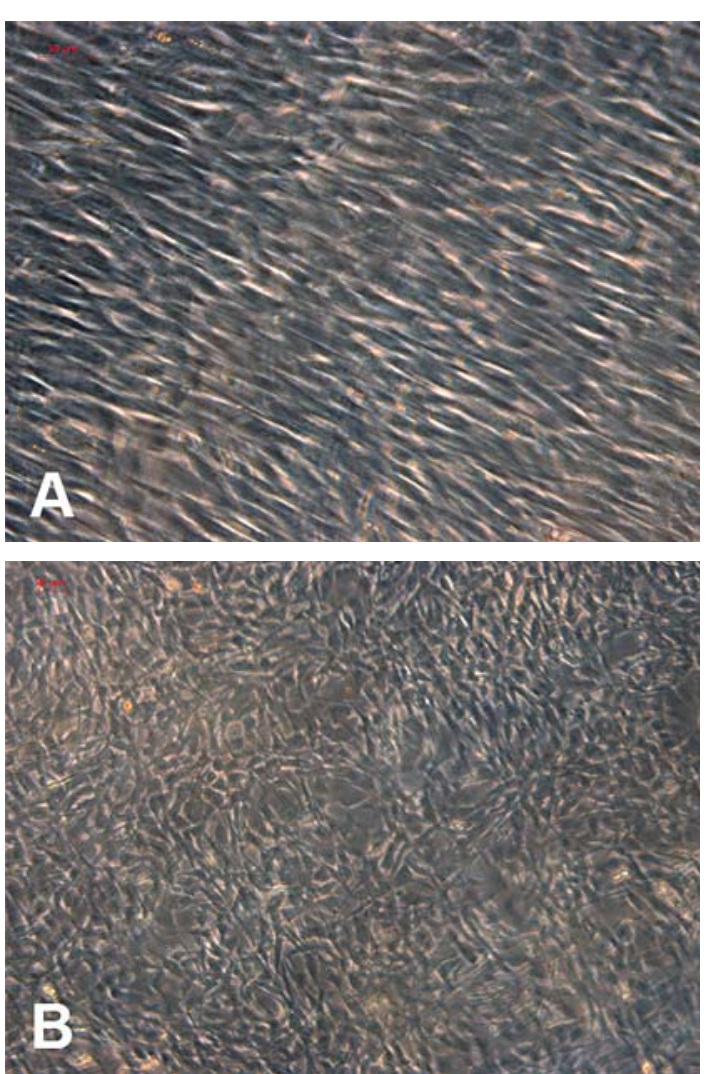

Figure 2. Effects of cyclic tensile stretch on the orientation of ASCs. ASCs of passage 3 were seeded at $2 \times 10^{5}$ per plate and cultured in osteogenic medium. A) After being subjected to cyclic tensile stretch for 4 days ( 17 min a day, $1 \mathrm{~Hz}, 2000 \mu \varepsilon$ ), ASCs presented $90 \%$ confluence and an orientation perpendicular to the strain axis. B) Cells in static controls and $6 \mathrm{~h}$ duration group oriented randomly (magnification, $\times 100$ )

loading had a significant influence on BMP-2 expression; 6 h' stretching up-regulated the BMP-2 expression three-fold more than the static group (Figure 4A).

The gene expression of Runx2 was observed at all time points in osteo-induced and mechanical stress loading condition. Figure 4B demonstrates that 17 min loading did not have a significant effect on Runx 2 mRNA expression, whereas loading for $6 \mathrm{~h}$ resulted in an approximately 5 -fold increase in Runx2 expression vs. controls. In addition, 6 h' loading had a significant effect on Runx2 expression vs. all time points of 17 -min loading. Further statistical results showed that there was a significant correlation between levels of mRNA expression of BMP-2 and Runx 2 in the same sample $(p<0.05)$, as assessed by Pearson's correlation tests.

\section{Discussion}

The results of phenotypic detection of ASCs is similar to most previous studies showing that the ASCs have similar phenotypes as BMSCs, and we have already proved the pluripotency of cells in our
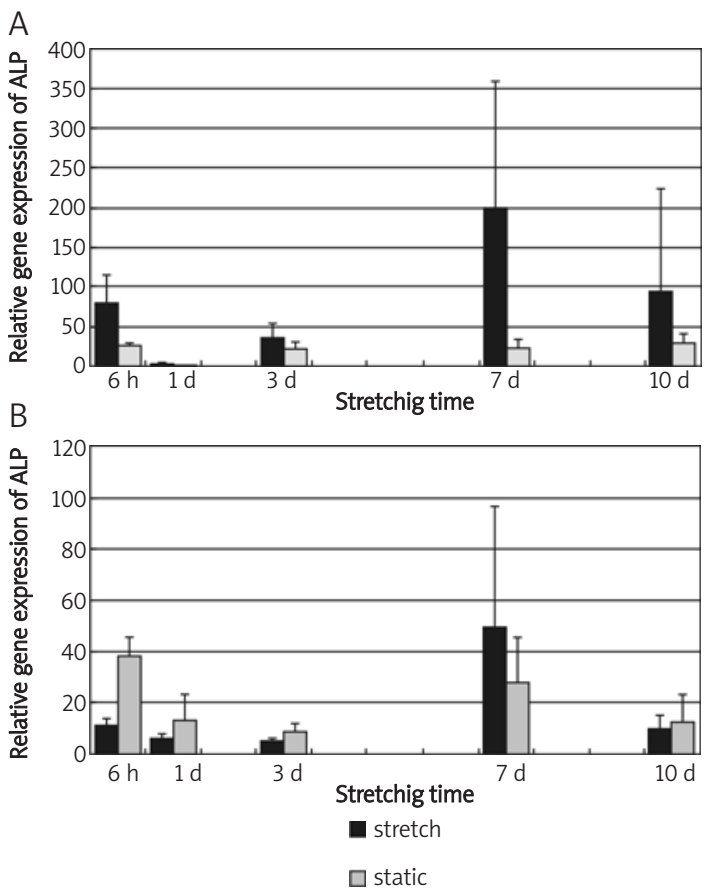

Figure 3. Effects of cyclic tensile stretch on osteogenic differentiation marker genes of ASCS. ALP (A) and OCN (B) gene expression are shown in different mechanical loading duration $(6 \mathrm{~h}$ continuous loading and 17 min every day for consecutive $1 \mathrm{~d}, 3 \mathrm{~d}, 7 \mathrm{~d}$, and $10 \mathrm{~d}$ ). Bars represent mean $\pm \mathrm{SEM} ; n=3$; Significant differences among the groups are noted by ${ }^{*} p<0.05$
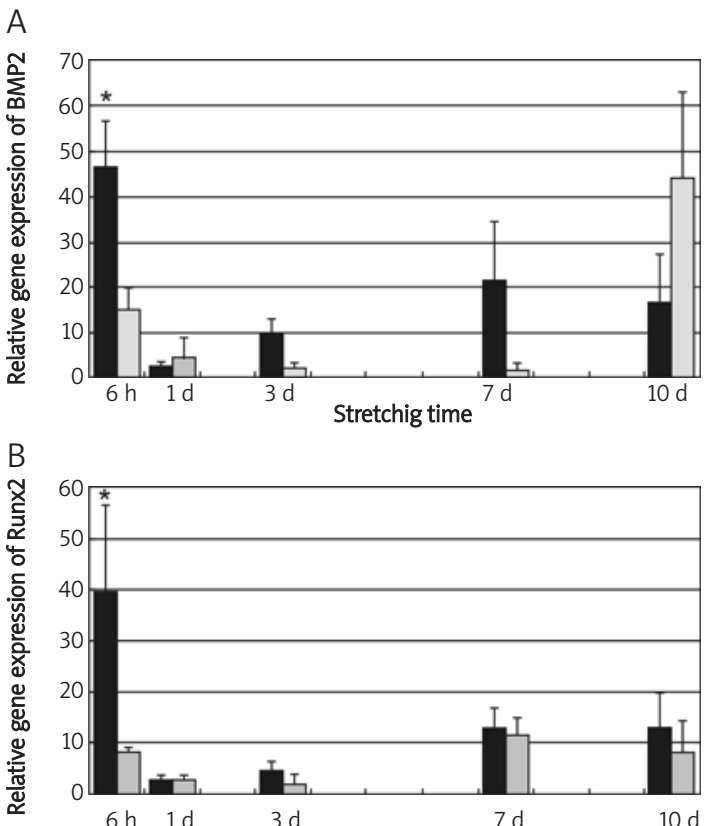

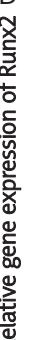

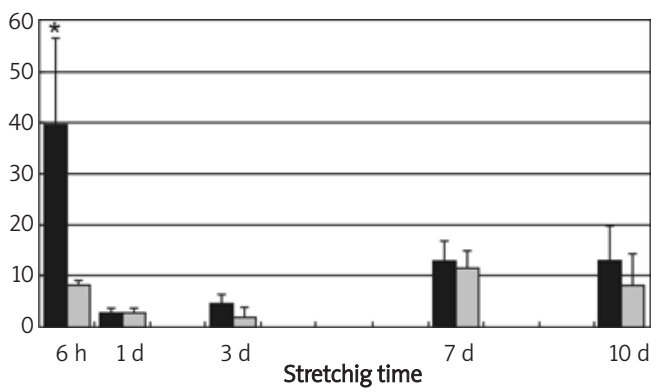

Figure 4. Effects of cyclic tensile stretch on osteogenic differentiation regulation genes of ASCs. BMP-2 (A) and Runx2 (B) gene expression are shown in different mechanical loading duration $6 \mathrm{~h}$ continuous loading and $17 \mathrm{~min}$ every day for consecutive $1 \mathrm{~d}, 3 \mathrm{~d}, 7 \mathrm{~d}$, and $10 \mathrm{~d}$ ). Bars represent mean $\pm \mathrm{SEM} ; n=3$; significant differences among the groups are noted by ${ }^{*} p<0.05$ 
former experiments [26]. Thereby ASCs could provide a promising alternative cell source for bone tissue engineering. To date, many papers have focused on the effects of mechanical stress on osteocytes, osteoblasts, BMSCs or the BMSC cell line $[4,7,27,28]$. However, only a few reports thus far have addressed this issue for ASCs [12-14]. Hence more investigations should be carried out on the mechanosensitivity of ASCs and its underlying mechanism.

Unfortunately, identification of mRNA markers characterizing the differentiation of ASCs towards an osteogenic lineage is further complicated by the known variability of cells from different individuals, different harvesting methods, and different passage of ASCs [29, 30]. Therefore, we use the same passage of the same explants from the same donor animal in order to have identical characteristics in all groups from the very beginning.

To detect the regulatory mechanism of mechanical stretch in the osteogenic differentiation of ASCs, cells exposed to two patterns of cyclic tensile stretch were subjected to analysis of BMP-2 and Runx2 mRNA expression and their correlation. BMP-2 has been proved to play a central role in the proliferation and differentiation of BMSCs [31]. The way that BMP-2 modulates osteogenic differentiation in MSCs varies widely, and one possible mechanism is the interaction with specific transcription factor Runx2, which has been indicated to function downstream of BMPs [17]. The presence of some cis-acting elements, which respond to the strain force in the promoter region of BMP-2, has been suggested on Runx2 [32]. Furthermore, it is indicated that BMP-2 could be enhanced by mechanical tension-stress in bone formation during distraction osteogenesis and could further induce in situ bone formation by a paracrine and autocrine mechanism [33]. Susperregui et al. [34] further found that uniaxial cyclic tensile strain alone was sufficient to increase expression of BMP-2 in the absence of chemical factors. We observed for the first time that cyclic tensile strain increased BMP-2 gene expression threefold and Runx2 fivefold after $6 \mathrm{~h}$ of mechanical loading. Moreover, the level of BMP-2 mRNA expression obtained a significant correlation with Runx2 mRNA expression. This suggests that cyclic tensile strain affects early differentiation marker Runx2 in ASCs, and it is possible that elevated expression of Runx 2 in ASCS is a consequence of the autocrine effect of BMP-2.

Different studies have demonstrated that mechanical loading could affect ALP and OCN gene expression. Increased ALP activity has been used in many studies as an indicator of osteoblastic differentiation of MSCs [18]. However, previous papers have also reported that osteoblastic subclones exhibited mineralization without increased ALP mRNA activity [35]. In addition, depressed ALP activity has been found after mechanical loading in bone-like cells, human osteoblasts and ASCs [3, 12, 36]. Furthermore, ALP has been reported to be biphasic in MSCs, with decreased activity prior to mineralization, and reaching the first peak concentration on day 14 during mechanical loading in BMSCs [37]. Osteocalcin is thought to be up-regulated at the onset of mineralization [18]. However, after cyclic mechanical loading of a long period or high magnitude, OCN gene expression or concentration was decreased [7, 38, 39], which is in accordance with the result in our study (Figure 3B). We also found that ALP gene expression was not significantly influenced under cyclic tensile stretch. Nevertheless, ALP gene expression holds a steady level in the osteogenic medium whereas after cyclic tensile stretch for 17 min every day ALP activity tends to increase and reach a peak on the $7^{\text {th }}$ day of mechanical loading. Thus, the trend of ALP is probably to increase by cyclic tension, and it may increase to a significantly high level in the later stage of osteogenesis.

We have also observed that mechanosensitivity of ASCs varies with the patterns of cyclic uniaxial mechanical stretch. Two different durations of mechanical loading, namely continuous $6 \mathrm{~h}$ for 1 day and 17 consecutive min for 10 days, were applied at a fixed frequency of $1 \mathrm{~Hz}$ and settled magnitude of $2000 \mu \varepsilon$. The latter loading pattern was expected to simulate a physiological oral masticatory condition [40]. The results indicated that the short duration of 17 min mechanical loading lasting for 10 days changes the orientation of ASCs, whereas the mechanical loading of long duration has significant effects on BMP-2, Runx2 and OCN gene expression. The particular change of orientation perpendicular to the long axis of stretching is consistent with the observations reported by Koike et al. [7] and Zhang et al. [41], who found that BMSCs responded to uniaxial cyclic stretch stimulation by reorganizing their orientations close to 100-110 degrees after a prolonged stimulation. Mechanical loading time is one of the determining parameters advocated by Kaspar et al. [3]. Most studies reach a consensus that the mechanical responsiveness of MSCs presents a type-[42], magnitude-[7], frequency-[43], cycle number-[3], and differentiation-[4] dependent manner; however, the most appropriate combination of the mechanical parameters is still obscure. One possibility is the different conditions in vitro and in vivo, that is, cells in vivo did not receive the same strain signal as in the cell stretching system since the bone matrix filters the physical load, and, moreover, the in vivo biomechanical condition is too complex to be 
simulated by in vitro mechanical loading models or algorithm models [44, 45].

We have to point out that one limitation of this study is the loading plate cultured in the semi-open culture dish, and the frequent change of culture location between culture dish and loading dish made it vulnerable to fungal contamination. This shortened the loading time to a significant degree and limited the loading days (17 min of daily loading) to less than 2 weeks. Despite its limitation, this study does suggest that cyclic strain could affect the osteogenesis of ASCs and the long duration of $6 \mathrm{~h}$ is more likely to have this effect.

In conclusion, we found that ASC s are sensitive to cyclic tensile strain. Cyclic tensile strain of 6 continuous h' duration rather than 17 min of consecutive stretching could significantly increase gene expression of BMP-2 and Runx2 and depress OCN mRNA expression. We indicate that ASCs may sense mechanical loading in a duration-dependent manner and cyclic tensile stretch may modulate the osteogenic differentiation of ASCs via the BMP-2 signalling pathway.

\section{Acknowledgments}

This work was supported in part by a grant of the National Natural Science Foundation of China (No. 30801304 and No. 30772448).

\section{References}

1. Gardner MJ, MC van der Meulen, D Demetrakopoulos, ER Myers, MP Bostrom. In vivo cyclic axial compression affects bone healing in the mouse tibia. Orthop Res 2006; 24: 1679-86.

2. Zaidi M. Skeletal remodeling in health and disease. Nat Med 2007; 13: 791-801.

3. Kaspar D, Seidl W, Neidlinger Wilke C, Beck A, Claes L, Ignatius A. Proliferation of human-derived osteoblast-like cells depends on the cycle number and frequency of uniaxial strain. J Biomech 2002; 35: 873-80.

4. Weyts FA, Bosmans B, Niesing R, van Leeuwen JP, Weinans $H$. Mechanical control of human osteoblast apoptosis and proliferation in relation to differentiation. Calcified Tissue Int 2003; 72: 505-12.

5. Simmons CA, Matlis S, Thornton AJ, Chen S, Wang CY, Mooney DJ. Cyclic strain enhances matrix mineralization by adult human mesenchymal stem cells via the extracellular signal-regulated kinase (ERK1/2) signaling pathway. J Biomech 2003; 36: 1087-96.

6. Li YJ, Batra NN, You L, et al. Oscillatory fluid flow affects human marrow stromal cell proliferation and differentiation. J Orthop Res 2004; 22: 1283-9.

7. Koike M, Shimokawa H, Kanno Z, Ohya K, Soma K. Effects of mechanical strain on proliferation and differentiation of bone marrow stromal cell line ST2. J Bone Min Metabol 2005; 23: 219-25.

8. Haasper C, Jagodzinski M, Drescher M, et al. Cyclic strain induces FosB and initiates osteogenic differentiation of mesenchymal cells. Exp Toxicol Pathol 2008; 59: 355-63.

9. Friedl G, Schmidt H, Rehak I, Kostner G, Schauenstein K, Windhager R. Undifferentiated human mesenchymal stem cells (hMSCs) are highly sensitive to mechanical strain: transcriptionally controlled early osteo-chondrogenic response in vitro. Osteoarthr Cartil 2007; 15: 1293-300.

10. Riddle RC, Taylor AF, Genetos DC, Donahue HJ. MAP kinase and calcium signaling mediate fluid flow-induced human mesenchymal stem cell proliferation. Am J Physiol Cell Physiol 2006; 290: C776-84.

11. Rhee ST, El-Bassiony L, Buchman SR. Extracellular signalrelated kinase and bone morphogenetic protein expression during distraction osteogenesis of the mandible: in vivo evidence of a mechanotransduction mechanism for differentiation and osteogenesis by mesenchymal precursor cells. Plast Reconstr Surg 2006; 117: 2243-9.

12. Knippenberg M, Helder MN, Doulabi BZ, Semeins CM, Wuisman PI, Klein Nulend J. Adipose tissue-derived mesenchymal stem cells acquire bone cell-like responsiveness to fluid shear stress on osteogenic stimulation. Tiss Eng 2005; 11: 1780-8.

13. Wall ME, Rachlin A, Otey C, Loboa EG. Human adiposederived adult stem cells upregulate palladin during osteogenesis and in response to cyclic tensile strain. Am J Physiol Cell Physiol 2007; 293: C1532-8.

14. Tjabringa GS, Vezeridis PS, Zandieh-Doulabi B, Helder MN, Wuisman PI, Klein Nulend J. Polyamines modulate nitric oxide production and COX-2 gene expression in response to mechanical loading in human adipose tissue-derived mesenchymal stem cells. Stem Cells 2006; 24: 2262-9.

15. Miyazono K, Maeda S, Imamura T. BMP receptor signaling: Transcriptional targets, regulation of signals, and signaling cross-talk. Cytok Growth Factor Rev 2005; 16: 251-63.

16. Fulford $\mathrm{MH}$. Signal transduction and mechanical stress. www.stke.org/cgi/content/full/sigtrans;2004/249/re12, 2004.

17. Wan M, Cao X. BMP signaling in skeletal development. Biochem Biophys Res Com 2005; 328: 651-7.

18. Zuk PA, Zhu M, Mizuno H. Multilineage cells from Human adipose tissue: implications for cell-based therapies. Tissue Eng 2001; 7: 211-28.

19. Zuk PA, Zhu M, Ashjian P, et al. Human adipose tissue is a source of multipotent stem cells. Mol Biol Cell 2002; 13: 4279-95.

20. Liu J, Liu T, Zhao Z, et al. Early responses of osteoblastlike cells to different mechanical signals through various signaling pathways. Biochem Biophys Res Commun 2006; 348: 1167-73.

21. Li Y, Song J, Yang P, Zou R, Fan X, Zhao Z. Establishment of a three-dimensional culture and mechanical loading system for skeletal myoblasts. Cell Biol Int 2008; doi:10.1016/j.cellbi.2008.11.002.

22. Owan I, Burr DB, Turner CH, et al. Mechanotransduction in bone: osteoblasts are more responsive to fluid forces than mechanical strain. Am J Physiol 1997; 273: C810-5.

23. Bochev I, Elmadjian G, Kyurkchiev D, et al. Mesenchymal stem cells from human bone marrow or adipose tissue differently modulate mitogen-stimulated B-cell immunoglobulin production in vitro. Cell Biol Int 2008; 32: 384-93.

24. de Ugarte DA, Alfonso Z, Zuk PA, et al. Differential expression of stem cell mobilization-associated molecules on multi-lineage cells from adipose tissue and bone marrow. Immunol Lett 2003; 89: 267-70.

25. Nakagami H, Maeda K, Morishita R, et al. Novel autologous cell therapy in ischemic limb disease through growth factor secretion by cultured adipose tissue-derived stromal cells. Arterioscler Thromb Vasc Biol 2005; 25: 2542-7. 
26. Lin Y, Jing W, Wu L, et al. Identification of osteo-adipo progenitor cells in fat tissue. Cell Prolifer 2008; 41: 803-12.

27. Westbroek I, Ajubi NE, Alblas MJ, et al. Differential stimulation of prostaglandin $\mathrm{G} / \mathrm{H}$ synthase-2 in osteocytes and other osteogenic cells by pulsating fluid flow. Biochem Biophys Res Commun 2000; 268: 414-9.

28. Jagodzinski M, Drescher M, Zeichen J, et al. Effects of cyclic longitudinal mechanical strain and dexamethasone on osteogenic differentiation of human bone marrow stromal cells. Eur Cell Mater 2004; 7: 35-41.

29. Oedayrajsingh VM, van Ham S, Knippenberg M, et al. Adipose tissue-derived mesenchymal stem cell yield and growth characteristics are affected by the tissueharvesting procedure. Cytotherapy 2006; 8: 166-77.

30. Wall ME, Bernacki SH, Loboa EG. Effects of serial passaging on the adipogenic and osteogenic differentiation potential of adipose-derived human mesenchymal stem cells. Tissue Eng 2007; 13: 1291-8.

31. Bi LX, Simmons DJ, Mainous E. Expression of BMP-2 by rat bone marrow stromal cells in culture. Cal Tissue Int 1999; 64: 63-8.

32. Nomura S, Yamamoto TT. Molecular events caused by mechanical stress in bone. Matrix Biol 2000; 19: 91-6.

33. Sato M, Ochi T, Nakase T, et al. Mechanical tension-stress induces expression of bone morphogenetic protein (BMP)-2 and BMP-4, but not BMP-6, BMP-7, and GDF-5 mRNA, during distraction osteogenesis. J Bone Min Res 1999; 14: 1084-95.

34. Susperregui AR, Vinñals F, Ho PW, Gillespie MT, Martin TJ, Ventura F. BMP-2 regulation of PTHrP and osteoclastogenic factors during osteoblast differentiation of C2C12 cells. J Cell Physiol 2008; 216: 144-52.

35. Wang D, Christensen K, Chawla K, Xko G, Krehsbach PH, Franceschi RT. Isolation and characterization of MC3T3-EI preosteoblast subclones with distinct in vitro and in vivo differentiation/mineralization potential. J Bone Mineral Res 1999; 14: 893-903.

36. Stanford CM, Morcuende JA, Brand RA. Proliferative and phenotypic responses of bone-like cells to mechanical deformation. J Orthop Res 1995; 13: 664-70.

37. Jansen JH, Weyts FA, Westbroek I, et al. Stretch-induced phosphorylation of ERK1/2 depends on differentiation stage of osteoblasts. J Cell Biochem 2004; 93: 542-51.

38. Kaspar D, Seidl W, Neidlinger Wilke C, Ignatius A, Claes L. Dynamic cell stretching increases human osteoblast proliferation and CICP synthesis but decreases osteocalcin synthesis and alkaline phosphatase activity. J Biomech 2000; 33: 45-51

39. Rath B, Nam J, Knobloch TJ, Lannutti JJ, Agarwal S. Compressive forces induce osteogenic gene expression in calvarial osteoblasts. J Biomech 2008; 41: 1095-103.

40. Frost HM. A 2003 update of bone physiology and Wolff's law for clinicians. Angle Orthodontist 2004; 74: 3-15.

41. Zhang L, Kahn CJ, Chen HQ, Tran N, Wang X. Effect of uniaxial stretching on rat bone mesenchymal stem cell: orientation and expressions of collagen types I and III and tenascin-C. Cell Biol Int 2008; 32: 344-52.

42. McGarry JG, Klein Nulend J, Mullender MG, Prendergast PJ. A comparison of strain and fluid shear stress in stimulating bone cell responses - a computational and experimental study. FASEB J 2005; 19: 482-4.

43. Jones DB, Nolte H, Ubbers Schol JG, Turner E, Veltel D. Biochemical signal transduction of mechanical strain in osteoblastlike cells. Biomaterials 1991; 12: 101-10.

44. Isaksson H, Comas O, van Donkelaar CC, et al. Bone regeneration during distraction osteogenesis: Mechano- regulation by shear strain and fluid velocity. J Biomech 2006; 40: 2002-11.

45. Kelly DJ, Prendergas PJ. Mechano-regulation of stem cell differentiation and tissue regeneration in osteochondral defects. J Biomech 2005; 38: 1413-22. 